University of Pennsylvania Carey Law School

Penn Law: Legal Scholarship Repository

Faculty Scholarship at Penn Law

2007

\title{
Abortion Access and Risky Sex Among Teens: Parental Involvement Laws and Sexually Transmitted Diseases
}

Jonathan Klick

University of Pennsylvania Carey Law School

Thomas Stratmann

George Mason University

Follow this and additional works at: https://scholarship.law.upenn.edu/faculty_scholarship

Part of the Community Health and Preventive Medicine Commons, Family Law Commons, Gender and Sexuality Commons, Law and Gender Commons, Medicine and Health Commons, and the Sexuality and the Law Commons

\section{Repository Citation}

Klick, Jonathan and Stratmann, Thomas, "Abortion Access and Risky Sex Among Teens: Parental Involvement Laws and Sexually Transmitted Diseases" (2007). Faculty Scholarship at Penn Law. 496. https://scholarship.law.upenn.edu/faculty_scholarship/496

This Article is brought to you for free and open access by Penn Law: Legal Scholarship Repository. It has been accepted for inclusion in Faculty Scholarship at Penn Law by an authorized administrator of Penn Law: Legal Scholarship Repository. For more information, please contact PennlawIR@law.upenn.edu. 


\title{
Abortion Access and Risky Sex Among Teens: Parental Involvement Laws and Sexually Transmitted Diseases
}

\author{
Jonathan Klick ${ }^{*}$ \\ Florida State University \\ Thomas Stratmann ** \\ George Mason University
}

Laws requiring minors to seek parental consent or to notify a parent prior to obtaining an abortion raise the cost of risky sex for teenagers. Assuming choices to engage in risky sex are made rationally, parental involvement laws should lead to less risky sex among teens, either because of a reduction of sexual activity altogether or because teens will be more fastidious in the use of birth control ex ante. Using gonorrhea rates among older women to control for unobserved heterogeneity across states, our results indicate that the enactment of parental involvement laws significantly reduces risky sexual activity among teenage girls. We estimate reductions in gonorrhea rates of $20 \%$ for Hispanics and $12 \%$ for whites. Although we find a relatively small reduction in rates for black girls, it is not statistically significant. We speculate that the racial heterogeneity has to do with differences in family structure across races.

\section{Introduction}

Teenage sex is often described in visceral or emotional terms, with reason and calculation playing little or no part in the decision to engage in sexual activity. Even some social scientists argue that the rational choice model inadequately describes sexual behavior among teens (e.g., Loewenstein 1996).

It is not surprising then that most of the discussion concerning laws that require a minor to obtain her parent's consent or, at least, to inform one of her parents that she plans to get an abortion centers on issues arising after the teen has engaged in risky sex. Supporters of these laws focus on parents' right to know about or directly influence their child's health-care decisions.

\footnotetext{
*College of Law, Florida State University. Email: jklick@law.fsu.edu.

**Department of Economics, George Mason University. Email: tstratma@gmu.edu.

The authors thank Marianne Bitler for access to her data on abortion laws as well as Ian Ayres, Tom Dee, Greg Mitchell, Rebecca Klick, Ted Joyce, Phil Levine, Jim Lindgren, David Paton, and workshop participants at Northwestern Law, George Mason Law, and ALEA for helpful comments.
}

The Journal of Law, Economics, \& Organization, Vol. 24, No. 1, doi:10.1093/jleo/ewm041

Advance Access publication September 4, 2007

(C) The Author 2007. Published by Oxford University Press on behalf of Yale University.

All rights reserved. For permissions, please email: journals.permissions@oxfordjournals.org 
Many supporters explicitly embrace the laws as part of an antiabortion agenda.

Opponents, on the other hand, frame their arguments in terms of the teenagers' rights. Also, a common rhetorical argument against the laws involves the suggestion that if teens are not responsible enough to decide for themselves whether or not to get an abortion, they are certainly not responsible enough to take care of a child (e.g., Schrag 2005).

However, it is possible that passage of parental involvement laws will affect the incentives teenagers face, inducing them to engage in less risky sex which would decrease the demand for abortion without increasing the incidence of teen motherhood. That is, if teens implicitly view abortion as a form of birth control, increasing the psychic costs of obtaining an abortion through parental involvement laws may induce teens to substitute toward other forms of birth control such as condoms, birth control pills, or abstaining from sex altogether. For this substitution effect to occur, however, teens must be forward looking in their decision-making process regarding their sexual activities, and parental involvement must represent a nontrivial increase in the total cost faced by a teen when obtaining an abortion.

We examine the effect of parental involvement laws on the decision to engage in risky sex using Centers for Disease Control (CDC) data on the incidence of gonorrhea among teenage girls. Using gonorrhea rates among adult women to control for contemporaneous variation in unobservable characteristics of the state population, we find that parental involvement laws reduce teen gonorrhea rates by $20 \%$ for Hispanics and $12 \%$ for white teens. The effects are smaller and not statistically significant for young black women. The results are robust to a wide range of empirical specifications. These results suggest that parental involvement laws reduce risky sexual behavior among teens as predicted by a model in which teens consider costs and benefits when deciding to engage in sexual activities.

In Section 2, we present the theoretical underpinnings of our inquiry, and in Section 3, we discuss the existing studies of the effects of parental involvement laws. Section 4 describes our data and identification strategy, and results are provided in Section 5.

\section{Teenage Sex and Incentives}

As described in Klick and Stratmann (2003) and Levine and Staiger (2004) abortion effectively serves an insurance function. That is, if unintended pregnancy is viewed as a risk of sex, having the option to abort the pregnancy lowers the cost of engaging in the sex. Further, in the decision to use some kind of ex ante birth control, such as condoms or birth control pills, the abortion option lowers the marginal benefit of contraception. Thus, if individuals are forward looking when making decisions regarding their sexual behavior, lowering the cost of abortion through legalization, subsidization, or technological progress that improves the safety of abortions will lead to an increase in risky sexual activity, on the margin, as individuals both have more sex and substitute away from ex ante birth control measures. 
Levine and Staiger (2004) present evidence in support of this incentive effect of abortion availability using changes in abortion laws in Eastern Europe to identify the effect. Specifically, they find that the pregnancy rate rises by about $25 \%$ when countries switched from laws that allowed abortion only when some medical or social hardship could be documented (e.g., carrying pregnancy to term would threaten the mother's life) to an abortion upon request system, relative to other countries that did not change their abortion laws at the same time.

There is some concern that the presence of illegal abortions might be driving this result. That is, under the more restrictive abortion policy, perhaps women simply procured illegal abortions. Pregnancies resolved in this manner would not show up in the pregnancy rate data, which is calculated as the number of abortions plus the number of live births per 1000 women aged $15-44$. If there are a large number of illegal abortions in countries which restrict access to abortion to only those cases where the mother's health is in danger, switching to an on-demand system would generate a spurious incentive effect as previously unobserved abortions would now appear in the official pregnancy rate even in the absence of any change in underlying behavior.

To mitigate this concern, Levine and Staiger (2004) also examine the effect of changing abortion access on the death rates of females aged 15-44 relative to males of the same age cohort. Assuming that illegal abortions tend to be less safe, if the switch from restricted abortion availability to on-demand abortion simply substituted safer abortions for unsafe abortions that would have been obtained illegally, there should have been a decrease in the female death rate. However, Levine and Staiger (2004) find no such increase, lending support to the incentive explanation for their pregnancy rate finding. However, it should be noted that death is a fairly rare outcome even in illegal abortions, so this test may not be very powerful in detecting any substitution between illegal and legal abortions.

Klick and Stratmann (2003) attempt to avoid the data problem illegal abortions represent in examining pregnancy rates by focusing on the incidence of sexually transmitted diseases (STDs) as a proxy for the incidence of risky sex (Klick 2004). That is, since more sex in the aggregate and the substitution toward sex without a condom will both lead to an increase in STDs, increasing abortion access will lead to an increase in STD incidence if individuals are forward looking in their decision to engage in risky sex. Klick and Stratmann(2003) examine the "double experiment" provided by US abortion policy to examine this link. They find that when Alaska, California, Hawaii, New York, and Washington legalized abortion on demand in the period 1969-1970, the gonorrhea and syphilis rates in those states rose significantly compared to the rest of the country. When the Supreme Court legalized abortion on demand nationwide in 1973, the STD gap between the early legalizers and other states disappeared.

Both studies, however, rely on aggregate data that do not allow the researchers to focus on teens specifically. It may be the case, in both instances, that support for the abortion as insurance model is driven by changes in the behavior of older individuals. If teens do not engage in rational calculation in their sex decisions, as suggested by Loewenstein (1996), because their behavior is 
determined almost entirely by biological forces or social construction ${ }^{1}$ or because they place excessive weight on the immediate benefits of sex while highly discounting the future costs (Loewenstein and Furstenberg 1991), then abortion access will not affect the sexual behavior of teens.

In addition to providing some insights into the potential differences between youth and adult decision-making processes, examining how teens react to changes in abortion access has practical implications as well. If the Klick and Stratmann (2003) results hold for teens, it would be useful for epidemiologists to explicitly model changes in abortion access in their models of the spread of STDs among teens. ${ }^{2}$ Further, such evidence might play a role in evaluating the welfare effects of abortion policies aimed at teens. More generally, the sensitivity of teens to the costs and benefits of sex is important for predicting the efficacy of any social policy meant to affect teen sexual behavior. ${ }^{3}$

In the context of laws requiring a young woman below the age of 18 to inform a parent or guardian about her decision prior to obtaining an abortion and laws requiring parental consent, the psychic costs of obtaining an abortion are raised if (1) the young woman's parents are unaware of the extent of her sexual activity, assuming the young woman expects them to be disapproving of such behavior, and/or (2) the young woman's parents are opposed to abortion morally (or she believes they are).

In the former case, requiring the young woman to inform her parents before getting an abortion prohibits her from concealing the pregnancy, which is proof of her behavior, from her parents. In the latter case, under a parental consent law, acquiring consent will be relatively difficult or, perhaps, impossible. In this regard, even under a notification law, there is likely to be some psychic cost to the young woman to the extent that her parents' feelings affect her own utility.

There is likely to be significant heterogeneity across groups with respect to these issues. For example, a young Catholic woman from a close family might be more likely to want to conceal her sexual behavior from her parents and she might suffer more anguish because her parents know she is having an abortion compared with a nonreligious young woman from a broken home.

\section{Prior Studies of Parental Involvement Laws}

Levine (2003) studies the effect of parental involvement laws on teen behavior by again focusing on pregnancy rates, abortion rates, and birth rates among 15to 17-year-olds as compared to women from older cohorts. He finds that the adoption of a parental involvement law, controlling for state and year effects, state-specific trends, and a host of other variables, leads to a statistically

1. Baumeister and Vohs (2004) suggest that these two perspectives have dominated the field of sexuality.

2. Weinstock et al. (2004) report that nearly half the newly reported STD infections in the United States each year are found among individuals in the 15-24 age range.

3. For example, Ayres and Baker (2005) suggest that criminalizing reckless sex (defined as having sex without a condom during one's first sexual experience with a particular person) would likely reduce both STD incidence and acquaintance rape. As they note, the benefits of such a law would be especially significant for teenage girls. 
significant decline in the abortion rate for the affected age-group but not for the age-groups that were not affected by the laws. His results for pregnancy and birth rates are more mixed with statistical significance in the estimates for the affected age-group depending on whether or not state-specific trends were included and what years of data were used to estimate the regressions; however, the signs of the coefficients in all the regressions, as well as the relative magnitudes of the coefficients in the 15- to 17-year-olds' regressions relative to the other age cohorts, are consistent with the hypothesis that parental involvement laws reduce risky sex among minors.

As in Levine and Staiger (2004), this study is neither able to rule out the possibility that teens substitute toward illegal or informal abortions when involvement laws go into effect nor able to rule out the possibility that teens obtain abortions out of state. Any of these possibilities could be driving the Levine results, in addition to the changing incentives hypothesis.

Levine (2004) is also able to examine whether the reduction in risky sex comes about because of an increase in the use of birth control or because of a reduction in sexual activity altogether. Using responses from the 1988 and 1995 National Survey of Family Growth, Levine finds that the adoption of parental involvement laws is associated with a reduction in the probability that a respondent in the 15- to 18-year age-group indicated that she had engaged in unprotected sexual activity. His results suggest that this reduction was driven by a reduction in individuals indicating they had failed to use contraception during the last time they had sexual intercourse, as opposed to not engaging in intercourse at all.

Tomal (1999) studied the effects of parental consent and notification laws separately. She finds that both kinds of involvement laws are associated with significantly higher birth rates and significantly lower abortion rates for both affected and unaffected teens, suggesting that there are important temporal effects that inhibit the isolation of the incentive effect of involvement laws on teens. For example, it could be the case that the adoption of parental involvement laws reflects an underlying antiabortion sentiment in the state that could make abortion relatively more costly for all individuals, regardless of whether the laws apply to them or not. The passage of such laws could track antiabortion protests that have the effect of driving abortion providers out of the state. Failure to control for these temporal effects could generate spurious correlations with the passage of involvement laws.

Bitler and Zavodny (2001) present results suggesting that parental involvement laws reduce the number of first-trimester abortions, leading to an increase in the proportion of abortions which take place after the first trimester. Their results in this regard are sensitive to whether or not they correct for autocorrelation. Medoff (1999) finds no statistically significant effect of involvement laws on state abortion rates (i.e., not broken down by trimester).

Joyce and Kaestner (1996) examine data from South Carolina, Tennessee, and Virginia, finding an effect of parental consent laws only in the case of South Carolina for nonblack minors on the order of a $10 \%$ reduction in the likelihood of obtaining an abortion. On the whole, they conclude that the effect of parental 
consent laws is small. This conclusion conflicts with those of Haas-Wilson (1996), who found that parental involvement laws were associated with a large decrease in the abortion rate for minors.

Interestingly, in a more recent article examining the experience of Texas whose parental notification law went into effect in 2000, Joyce et al. (2006) find a significant effect on the abortion rates of those women covered by the law relative to 18 -year-old women.

\section{Gonorrhea Rates as a Proxy for Risky Sexual Behavior}

Interestingly, by focusing on pregnancy rates and abortion rates as the dependent variable, all the studies discussed in Section 3 suffer from an inability to deal with the problem of illegal abortions. Again, if parental involvement laws simply push minors into obtaining illegal abortions, the estimates described above could simply involve spurious correlations as illegal or informal (e.g., inflicting damage to the young woman's abdomen in hopes of generating a miscarriage) abortions drop out of the abortion rate and pregnancy rate data. Although the Levine and Staiger (2002) analysis of female death rates cuts against this possibility, they cannot rule it out if death from illegal and informal abortions is fairly rare.

To avoid this problem, we adopt the strategy originated in Klick and Stratmann (2003) of focusing on STD rates as our measure of risky sexual behavior. Specifically, we use the incidence of gonorrhea among women under the age of 20 as our proxy for risky sex. The choice of gonorrhea is driven by a handful of factors. First, along with syphilis and chlamydia, gonorrhea is the only STD for which the CDC has consistent data by age-group and by race. Gonorrhea has a very short incubation period, is easily cured, and, other than mother-to-infant infections, is only transmitted by sexual intercourse (Sen 2003).

We avoided using chlamydia because the data are only available after 1996, which would not allow us to exploit many of the parental involvement law changes. Syphilis also was rejected, given some of the peculiar characteristics of the disease that make it unattractive for our purposes. Specifically, syphilis has largely been eradicated among women with much of the disease's incidence occurring among the homosexual male population for whom pregnancy concerns are not a cost of risky sex (Klick and Stratmann 2003).

The dependent variable we focus on then is the number of female gonorrhea cases per 100,000 female population in a state in the under-20 age category for the years 1981 through 1998. Although this "treatment group" is slightly overinclusive with respect to the parental involvement laws, which apply to individuals under 18 years of age, the data do not allow us to examine gonorrhea rates for only those under 18. Inclusion of 18- and 19-year-olds will serve to bias any estimate of the causal effect of parental involvement laws toward zero. We perform separate regressions for Hispanic teenagers, black teenagers, and white teenagers since the underlying gonorrhea rates differ substantially by race.

Our parental involvement law variable comes from Bitler and Zavodny (2001) and equals 1 for a year in which the state had either a parental notification or consent law in effect for the entire year. For years in which a state 
adopted or got rid of such a law, the variable measures the fraction of the year during which the law was in effect. All other state-year combinations take the value of $0 .^{4}$

To control for unobservable effects, we include the gonorrhea rate among women in the 20 and older age-group. Although it is possible that there could be cross-group infections which would contaminate our control group, any such cross-group effects will bias our estimate of the effect of involvement laws on the under- 20 gonorrhea rate toward zero. We are essentially implementing the specification Levine and Staiger (2002) used to examine the effect of abortion laws on female death rates. ${ }^{5}$ We also control for time-invariant state effects and year effects that are common to all states as well as state-specific trends. Descriptive statistics by race are presented in Table 1.

The regressions we run take the following form, where $s$ denotes the state, $t$ denotes the year, and $(s \times t)$ captures the state-specific trends with $a$ denoting the age-group (under 20; 20 and older):

$$
\text { rate }_{s t a_{\text {under } 20}}=\alpha \cdot \operatorname{law}_{s t}+\beta \cdot \text { rate }_{s t a_{20+}}+\lambda_{s}+\tau_{t}+\Theta \cdot\left(s_{s} \times t\right),
$$

where the regressions are run separately by race and are weighted by the relevant race's population of women under the age of $20 .^{6}$

\section{Is Teen Sexual Behavior Sensitive to Incentives?}

We present the results of our analysis in Table 2. In addition to the statespecific trend specification laid out above, we also present results when we drop state trends. ${ }^{7}$ Further, given the concerns raised by Bertrand et al. (2004) about serial correlation in difference-in-difference studies, we present three sets of standard errors (SEs) for each coefficient. In addition to robust SEs, which allow for heteroskedasticity, we implement two of the serial correlation remedies suggested by Bertrand et al. In the first, we calculate the Newey-West Heteroskedastic-Autocorrelation Consistent estimator of the SEs, choosing the potential lag structure optimally, as described in Stock and Watson (2003:505-506). We also present SEs clustered by state.

4. Bitler and Zavodny construct their data from Merz et al. (1995) and Blank et al. (1996), updating subsequent years with data from NARAL and the Alan Guttmacher Institute.

5. The duplication is not exact. Levine and Staiger (2002) regressed $\ln$ (female death rate/male death rate) on a vector of explanatory variables $X$, which is equivalent to regressing $\ln$ (female death rate) on vector $X$ with the addition of $\ln$ (male death rate) as an explanatory variable. The results we present in Section 5 are robust to regressing $\ln$ (under-20 gonorrhea rate) on the involvement law variable and $\ln (20$ and over gonorrhea rate) with state- and year-fixed effects and state-specific trends. We chose to present the nonlogged specification since there are many observations with a 0 under-20 gonorrhea rate which would be lost in the log specification.

6. The results that follow are effectively unchanged if we also include a number of state-level covariates, such as per capita income, education levels, religious composition, and so on. Since we include gonorrhea rates for women 20 years and older, any generic effect of these state-level covariates should be controlled through their effect on adult gonorrhea rates.

7. We also examined specifications including state-specific quadratic and cubic trends. These specifications generated results almost identical to those presented for the state-specific linear trend case. These results are available upon request. 
Table 1. Descriptive Statistics

\begin{tabular}{|c|c|c|c|}
\hline Variable & Description & Mean & SD \\
\hline Involvement Law & $\begin{array}{l}\text { Percent of year state enforced a parental } \\
\text { notification or consent law regarding } \\
\text { abortions for minors }\end{array}$ & 0.280 & 0.439 \\
\hline Consent Law & $\begin{array}{l}\text { Percent of year state had a parental } \\
\text { consent law in place regarding } \\
\text { abortions for minors }\end{array}$ & 0.175 & 0.374 \\
\hline Enjoined Law & $\begin{array}{l}\text { Percent of year state had a parental } \\
\text { involvement law in place but its } \\
\text { enforcement was enjoined by court } \\
\text { action or it was effectively enjoined by } \\
\text { a state attorney general's public } \\
\text { decision not to enforce the law }\end{array}$ & 0.197 & 0.389 \\
\hline \multicolumn{4}{|l|}{ Hispanic (female) } \\
\hline $\begin{array}{l}\text { Gonorrhea } \\
\text { rate }_{\text {under } 20}\end{array}$ & $\begin{array}{l}\text { Number of gonorrhea cases among } \\
\text { Hispanic women below the age of } 20 \\
\text { per } 100,000 \text { Hispanic women under } \\
\text { the age of } 20 \text { in the state }\end{array}$ & 57.402 & 65.774 \\
\hline Gonorrhea rate $20+$ & $\begin{array}{l}\text { Number of gonorrhea cases among } \\
\text { Hispanic women } 20 \text { or older per } \\
\text { 100,000 Hispanic women } 20 \text { or older } \\
\text { in the state }\end{array}$ & 64.099 & 83.249 \\
\hline \multicolumn{4}{|l|}{ Hispanic (male) } \\
\hline $\begin{array}{l}\text { Gonorrhea } \\
\text { rate }_{\text {under } 20}\end{array}$ & $\begin{array}{l}\text { Number of gonorrhea cases among } \\
\text { Hispanic men below the age of } 20 \text { per } \\
100,000 \text { Hispanic men under the age } \\
\text { of } 20 \text { in the state }\end{array}$ & 42.945 & 57.731 \\
\hline $\begin{array}{l}\text { Gonorrhea } \\
\text { rate }_{20+}\end{array}$ & $\begin{array}{l}\text { Number of gonorrhea cases among } \\
\text { Hispanic men } 20 \text { or older per } 100,000 \\
\text { Hispanic men } 20 \text { or older in the state }\end{array}$ & 123.554 & 181.157 \\
\hline \multicolumn{4}{|l|}{ Black (female) } \\
\hline $\begin{array}{l}\text { Gonorrhea } \\
\text { rate }_{\text {under } 20}\end{array}$ & $\begin{array}{l}\text { Number of gonorrhea cases among black } \\
\text { women below the age of } 20 \text { per } \\
100,000 \text { black women under the age } \\
\text { of } 20 \text { in the state }\end{array}$ & 927.223 & 694.490 \\
\hline $\begin{array}{c}\text { Gonorrhea } \\
\text { rate }_{20+}\end{array}$ & $\begin{array}{l}\text { Number of gonorrhea cases among black } \\
\text { women } 20 \text { or older per } 100,000 \text { black } \\
\text { women } 20 \text { or older in the state }\end{array}$ & 772.665 & 602.098 \\
\hline \multicolumn{4}{|l|}{ Black (male) } \\
\hline $\begin{array}{l}\text { Gonorrhea } \\
\text { rate }_{\text {under } 20}\end{array}$ & $\begin{array}{l}\text { Number of gonorrhea cases among black } \\
\text { men below the age of } 20 \text { per } 100,000 \\
\text { black men under the age of } 20 \text { in the state }\end{array}$ & 748.087 & 642.344 \\
\hline $\begin{array}{l}\text { Gonorrhea } \\
\text { rate }_{20+}\end{array}$ & $\begin{array}{l}\text { Number of gonorrhea cases among black } \\
\text { men or older per 100,000 black men } 20 \text { or } \\
\text { older in the state }\end{array}$ & 1686.458 & 1308.767 \\
\hline \multicolumn{4}{|l|}{ White (female) } \\
\hline $\begin{array}{l}\text { Gonorrhea } \\
\text { rate }_{\text {under } 20}\end{array}$ & $\begin{array}{l}\text { Number of gonorrhea cases among } \\
\text { white women below the age of } 20 \text { per } \\
100,000 \text { white women under the age of } \\
20 \text { in the state }\end{array}$ & 80.194 & 87.968 \\
\hline
\end{tabular}


Table 1. Continued

\begin{tabular}{|c|c|c|c|}
\hline Variable & Description & Mean & SD \\
\hline $\begin{array}{l}\text { Gonorrhea } \\
\text { rate }_{20+}\end{array}$ & $\begin{array}{l}\text { Number of gonorrhea cases among white } \\
\text { women } 20 \text { or older per } 100,000 \text { white } \\
\text { women } 20 \text { or older in the state }\end{array}$ & 47.432 & 56.007 \\
\hline \multicolumn{4}{|l|}{ White (male) } \\
\hline $\begin{array}{l}\text { Gonorrhea } \\
\text { rate }_{\text {under } 20}\end{array}$ & $\begin{array}{l}\text { Number of gonorrhea cases among white } \\
\text { men below the age of } 20 \text { per } 100,000 \\
\text { white men under the age of } 20 \text { in the state }\end{array}$ & 31.406 & 64.709 \\
\hline $\begin{array}{c}\text { Gonorrhea } \\
\text { rate }_{20+}\end{array}$ & $\begin{array}{l}\text { Number of gonorrhea cases among white } \\
\text { men } 20 \text { or older per } 100,000 \text { white men } \\
20 \text { or older in the state }\end{array}$ & 74.929 & 162.125 \\
\hline
\end{tabular}

Involvement Law data come from Bitler and Zavodny (1999), and the gonorrhea data were generated by the CDC, Division of Sexually Transmitted Diseases.

For all races and for all specifications, we find that the effect of parental involvement laws on gonorrhea rates for women under the age of 20 is negative. However, none of the specifications for black gonorrhea rates generates a statistically significant coefficient on the parental involvement law. For each of the specifications for Hispanic and white gonorrhea rates that include statespecific trends (including those with quadratic or cubic state-specific trends which are not reported here), there is a statistically significant negative effect of parental involvement laws on female teen gonorrhea rates. For each race, the coefficient's magnitude is larger when state trends are included, suggesting

Table 2. The Effect of Parental Involvement Laws on Female Teenage Gonorrhea Rates per 100,000 Population

\begin{tabular}{|c|c|c|c|c|c|c|}
\hline & Hispanic & $\begin{array}{l}\text { Gonorrhea } \\
\text { rate }_{\text {under } 20}\end{array}$ & Black & $\begin{array}{l}\text { Gonorrhea } \\
\text { rate }_{\text {under } 20}\end{array}$ & White & $\begin{array}{l}\text { Gonorrhea } \\
\text { rate }_{\text {under } 20}\end{array}$ \\
\hline \multirow[t]{4}{*}{ Involvement law } & -4.905 & -12.048 & -36.610 & -40.723 & -0.816 & -9.541 \\
\hline & $(4.306)$ & $(5.801)^{\star \star}$ & $(35.041)$ & $(40.497)$ & $(2.473)$ & $(2.765)^{\star \star \star}$ \\
\hline & {$[5.001]$} & {$[5.560]^{\star \star}$} & [43.618] & $(47.239)$ & [3.247] & {$[3.130]^{\star \star \star}$} \\
\hline & $\{6.350\}$ & $\{5.648\}^{\star \star}$ & $\{57.081\}$ & $\{69.777\}$ & $\{4.814\}$ & $\{5.309\}^{*}$ \\
\hline \multirow[t]{4}{*}{ Gonorrhea rate $20+$} & 0.560 & 0.536 & 0.971 & 0.930 & 1.415 & 1.407 \\
\hline & $(0.025)^{\star \star \star}$ & $(0.038)^{\star \star \star}$ & $(0.043)^{\star \star \star}$ & $(0.056)^{\star \star \star}$ & $(0.043)^{\star \star \star}$ & $(0.068)^{\star \star \star}$ \\
\hline & {$[0.028]^{\star \star \star}$} & {$[0.039]^{\star \star \star}$} & {$[0.050]^{\star \star \star}$} & {$[0.062]^{\star \star \star}$} & {$[0.053]^{\star \star \star}$} & {$[0.077]^{\star \star \star}$} \\
\hline & $\{0.034\}^{* * *}$ & $\{0.047\}^{\star \star \star}$ & {$[0.068]^{\star \star \star}$} & $\{0.080\}^{\star \star *}$ & $\{0.083\}^{\star \star \star}$ & $\{0.125\}^{\star \star \star}$ \\
\hline State effects & Yes & Yes & Yes & Yes & Yes & Yes \\
\hline Year effects & Yes & Yes & Yes & Yes & Yes & Yes \\
\hline State trends & None & Linear & None & Linear & None & Linear \\
\hline Observations & 911 & 911 & 912 & 912 & 912 & 912 \\
\hline$R^{2}$ & 0.920 & 0.938 & 0.938 & 0.947 & 0.945 & 0.962 \\
\hline
\end{tabular}

Robust SEs are given in parentheses; Newey-West Heteroskedastic-Autocorrelation Consistent (HAC) SEs are given in brackets; and SEs clustered by state are given in curly brackets. All regressions were weighted using the population of females under the age of 20 of the given race for each state. For the Newey-West HAC estimators of the SEs, we chose the lag structure optimally as discussed in Stock and Watson (2003:505-506).

${ }^{\star \star \star} p<0.01 ;{ }^{\star \star} p<0.05 ;{ }^{\star} p<0.10$. 
that involvement laws tend to be adopted as teen gonorrhea rates are already trending downward. Thus, inclusion of state trends may help to mitigate any potential simultaneity bias.

For young Hispanic women, parental involvement laws are associated with a decline of 12 cases of gonorrhea per 100,000 population. This effect is both statistically significant $(p=0.038)$ and of practical importance as it represents a decline of about $21 \%$ relative to the average Hispanic teen female gonorrhea rate. The effect for young white women, a reduction of 9.5 cases per 100,000 population) is also statistically significant $(p=0.001)$ and represents a decline of about $12 \%$ relative to the average rate. The statistical significance of these effects is robust to the various SE calculations. We also employed the Arellano-Bond (1991) estimator to explicitly model the potentially dynamic causal effect, allowing for up to a 2-year distributed lag, and the results were essentially the same (not reported). ${ }^{8}$ Although the effect among young black women generates the coefficient with the largest magnitude $(-41)$, it is not statistically significant and the relative effect is fairly small, representing a reduction of only $4 \%$.

For all races, the rate of gonorrhea among women 20 and older is positively and significantly related to the under- 20 gonorrhea rate. The regressions all explain more than $93 \%$ of the variation in the data.

\subsection{More General Time Effect}

As a robustness check on our Table 2 results, we also estimated models allowing for more general time effects. Specifically, in the difference-in-difference model presented above, we are only able to estimate time-invariant state effects. However, if unobservable state characteristics are changing over time and those effects are related to the passage of parental involvement laws, our results will suffer from an omitted-variables bias. For example, if views about abortion among a state's residents are changing over time, we may find that increasing social conservatism has both an effect on sexual behavior (e.g., less premarital sex, more monogamy, etc.) and the adoption of public policy (e.g., parental involvement laws). This simultaneity would generate a positive association between abortion laws and gonorrhea rates even if there is no true effect of parental involvement laws on teenage sexual behavior.

Arguably, controlling for the gonorrhea rates of those aged 20 and older mitigates this concern to some degree, as social pressures affecting teens would likely affect older women as well. However, in the specifications provided in Table 2, we pool the relationship between teen gonorrhea rates and adult gonorrhea rates in one coefficient that is common to all states and years. A more general model would allow for these social effects to differ by state, as well as over time.

To allow for this generality, we present a difference-in-difference-indifference (DDD) model which uses the adult gonorrhea rates as a within-state

8. The xtabond routine in Stata does not allow for weights, so the resulting magnitudes are not directly comparable in principle, though they differed very little in magnitude and did not differ at all in sign or statistical significance. The Arellano-Bond (1991) diagnostic statistic suggested that the series exhibits a 1-year lag structure. 
control group for each observation of teenage female gonorrhea rates. That is, we now estimate a regression that includes separate year effects for each state, separate year effects for each age-group, as well as age-group-specific state effects. We also allow for age-group-specific state trends. In this specification, we are identifying the effect of a parental involvement law by examining the average change in the relationship between teen and adult gonorrhea rates before and after the adoption of the law, net of any contemporaneous changes in the relationship in nonadopting states as well as any preexisting trends in the relationship in adopting states.

More formally, we estimate:

rate $_{s t a}=\alpha \cdot \operatorname{law}_{s t a}+\lambda_{s a}+\tau_{t a}+T_{s t}+\Theta \cdot\left(s_{s a} \times t\right)$,

where law $_{\text {sta }}$ takes the value of the percent of year $t$ in which state $s$ had a parental involvement law in place for the observations on teenage female gonorrhea rates and zero for all other observations (i.e., all adult female gonorrhea rates and teenage female gonorrhea rates in states with no parental involvement law). $\lambda_{s a}$ represents the time-invariant age-specific state-fixed effects; $\tau_{t a}$ represents the age-group-specific year dummies that are common to all states; $T_{s t}$ represents the state-specific year dummies; the last term represents the agegroup-specific and state-specific trends.

We present the results from this DDD specification in Table 3. Once again, we find that all races exhibit a negative effect of parental involvement laws on teenage female gonorrhea rates. Again, the results are not statistically significant for black women, even though the magnitude of the effect is the largest for this race. For Hispanics and whites, statistical significance is sensitive to the time trend included, with the Hispanic coefficient being significant in the no-trend model, but not the others, whereas the white coefficient is significant in all the trend models (including the quadratic- and cubic-trend models not presented here). For our purposes, it is most important to note that time-varying unobserved state effects do not appear to be biasing the difference-in-difference results presented in Table 2, since the more general DDD specifications of Table 3 generate coefficients that are generally as large or larger than the Table 2 results. ${ }^{9}$

9. Parallel work by Dee and Sen (2006) finds no effect of parental involvement laws on teen gonorrhea rates in a triple-differences framework. This difference arises primarily because they do not include age-specific state trends in their triple-difference specifications (and they do not examine rates among Hispanics). They also raise some concerns regarding the use of weighted least squares (WLS), suggesting that weighting might be improper in this context since the magnitude of the point estimates differs between the ordinary least squares (OLS) and WLS specifications by more than $50 \%$. Interestingly, in the specifications with age-group-specific state trends, the difference in point estimates between the OLS and WLS triple-difference specifications is much smaller, mitigating their concerns about weighting. On the arguments for using WLS in this context, see Greene (2000) and Wooldridge (2003), who argue that WLS provides greater efficiency in some contexts. Specifically, when using rates as the dependent variable, states with larger populations are likely to have lower error variance in their rates. It is also arguable, from a practical standpoint, that when estimating average treatment effects on incidence rates, weighted estimators are more relevant, given the large differences in state populations. 


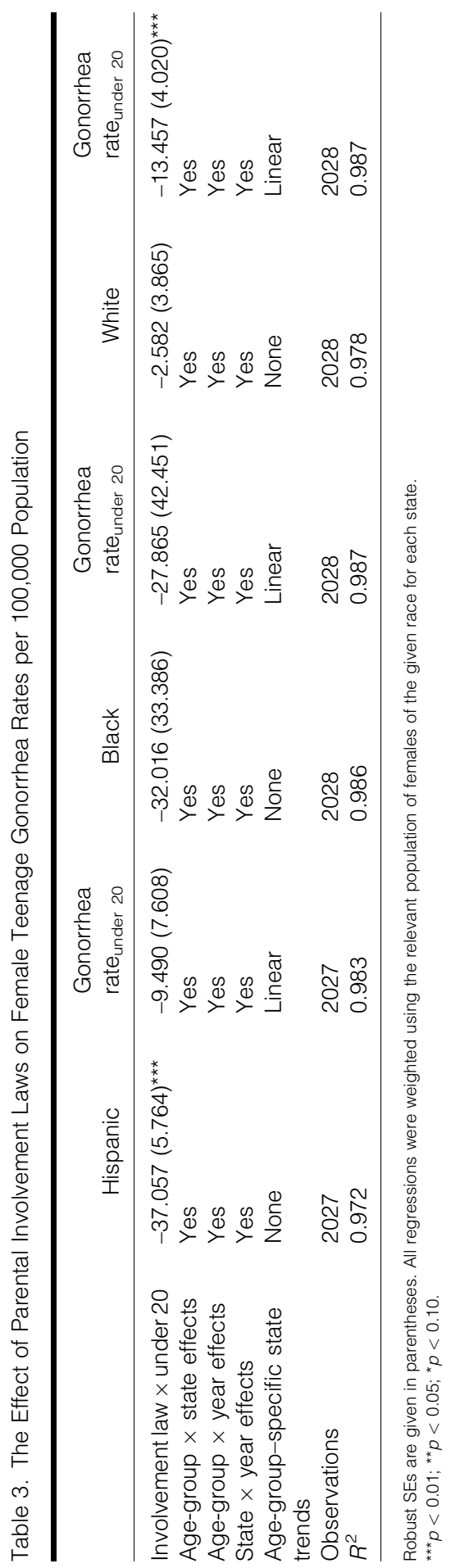


Table 4. The Effect of Parental Involvement Laws on Female Teenage Gonorrhea Rates per 100,000 Population Effect of Enjoining Parental Involvement Laws

\begin{tabular}{|c|c|c|c|}
\hline & $\begin{array}{c}\text { Hispanic gonorrhea } \\
\text { rate }_{\text {under } 20}\end{array}$ & $\begin{array}{c}\text { Black gonorrhea } \\
\text { rate }_{\text {under } 20}\end{array}$ & $\begin{array}{l}\text { White gonorrhea } \\
\text { rate } \\
\text { under } 20\end{array}$ \\
\hline Involvement law & $-13.846(5.988)^{\star \star}$ & $-33.164(43.059)$ & $-13.275(3.545)^{\star \star \star}$ \\
\hline Enjoined law & $-4.476(3.038)$ & $12.840(37.972)$ & $-5.932(2.867)^{\star \star}$ \\
\hline Gonorrhea rate $_{20+}$ & $0.538(0.038)^{\star \star \star}$ & $0.931(0.056)^{\star \star \star}$ & $1.404(0.067)^{\star \star \star}$ \\
\hline State effects & Yes & Yes & Yes \\
\hline Year effects & Yes & Yes & Yes \\
\hline State trends & Linear & Linear & Linear \\
\hline Observations & 911 & 912 & 912 \\
\hline$R^{2}$ & 0.939 & 0.947 & 0.963 \\
\hline
\end{tabular}

Robust SEs are given in parentheses. As above, all regressions are weighted using the population of females under the age of 20 for the given race for each state.

${ }^{\star \star \star} p<0.01 ;{ }^{* \star} p<0.05 ;{ }^{*} p<0.10$.

\subsection{The Effects of Enjoining a Parental Involvement Law}

Although the DDD results provide some comfort that our treatment effect is not driven by time-varying unobservables, there is another test we can exploit to examine the potential endogeneity of parental involvement laws. In a number of states, after the legislature passes an involvement law, state courts have ruled the laws to be impermissible under the federal or state constitution, enjoining their enforcement or the state attorney general has made a similar decision, effectively enjoining the law due to its public decision not to enforce the law. These decisions to enjoin the law will be largely orthogonal to underlying voter sentiment. Thus, if this sentiment is driving our treatment effect, we should find that the effect of enjoining the law has approximately the same effect on gonorrhea rates as does the law's passage.

On the other hand, if the effect is reduced, it suggests that the law itself, independent of any underlying social pressures or attitudes, has an effect on teenage sexual behavior through the channels discussed above. We likely would not expect the effect to drop to zero if the law is enjoined for a few reasons. First, the timing of the enjoinment is precise, whereas the gonorrhea data are aggregated annually. Second, if teens are making decisions probabilistically, they will recognize the potentially temporary nature of enjoining the law since a higher court may reverse the decision quickly or the legislature may redraft the law to respond to the decision to enjoin the law.

In Table 4, we investigate this test, showing that the coefficient on an enjoined law is substantially lower than the effect of an enforced law. Specifically, for Hispanics and whites, the enjoined law generates a coefficient that is roughly one-third as large as the coefficient on the enforced law. The enjoined law coefficient is not statistically significant for Hispanics but it is for whites, though the difference between the enforced law coefficient and the enjoined law coefficient for whites is statistically significant at the $1 \%$ level. For the regressions examining black gonorrhea rates, we find a positive coefficient on the enjoined laws, though it is not statistically significant, perhaps further indicating the differing dynamics of black gonorrhea rates relative to the other races examined. 
Table 5. The Effect of Parental Involvement Laws on Female Teenage Gonorrhea Rates per 100,000 Population Notification and Consent

\begin{tabular}{|c|c|c|c|}
\hline & $\begin{array}{c}\text { Hispanic gonorrhea } \\
\text { rate } \\
\text { under } 20\end{array}$ & $\begin{array}{l}\text { Black gonorrhea } \\
\text { rate }_{\text {under } 20}\end{array}$ & $\begin{array}{l}\text { White gonorrhea } \\
\text { rate under } 20\end{array}$ \\
\hline Involvement law & $-12.957(8.057)$ & $-191.032(63.869)^{\star \star *}$ & $-8.984(3.621)^{\star \star \star}$ \\
\hline Consent law & $2.094(10.776)$ & $217.381(71.759)^{\star \star \star}$ & $-0.991(5.591)$ \\
\hline Gonorrhea rate $_{20+}$ & $0.536(0.038)^{\star \star \star}$ & $0.930(0.056)^{\star \star \star}$ & $1.406(0.068)^{\star \star \star}$ \\
\hline State effects & Yes & Yes & Yes \\
\hline Year effects & Yes & Yes & Yes \\
\hline State trends & Linear & Linear & Linear \\
\hline Observations & 911 & 912 & 912 \\
\hline$R^{2}$ & 0.938 & 0.947 & 0.962 \\
\hline
\end{tabular}

Robust SEs are given in parentheses. As above, all regressions are weighted using the population of females under the age of 20 for the given race for each state.

${ }^{\star \star \star} p<0.01 ;{ }^{\star \star} p<0.05 ;{ }^{*} p<0.10$.

\subsection{Differences Across Categories of Laws}

We have treated parental involvement laws generically until now. However, there may be differences between notification laws and consent laws. Effectively, both laws have a notification component since it would not be possible to obtain parental consent without simultaneously providing notification. However, consent laws may provide an additional deterrent if parents are likely to stop their daughter from receiving an abortion.

To examine how much of the effect we identify is purely a notification effect, we reran the Table 2 regressions adding a variable taking the value of the percent of a year the state had a parental consent law in effect. Thus, our involvement law coefficient will indicate the effect of the notification requirement on behavior, whereas the consent coefficient will indicate the marginal effect from also requiring parental consent for abortion access.

As shown in Table 5, for both Hispanics and whites, we find that all the identified effect comes from the notification requirement. For neither race is the consent coefficient statistically significant. Once again, however, the black regressions exhibit a different pattern. Although in these regressions black female teen gonorrhea rates exhibit a statistically significant decline when notification is required, they actually exhibit a statistically significant increase when consent is required. We have no intuition for this result, but it does seem to further indicate that the dynamics of black gonorrhea rates differ from those of Hispanics and whites.

\subsection{Effects on Male Gonorrhea Rates}

As one further robustness check on our results, we also examined the effect of parental involvement laws on gonorrhea rates among teenage males. In principle, since it seems likely that most individuals have sexual relations within their own peer group, if the posited causal mechanism is generating the results presented above, we should find a similar effect among males. If females are deterred from having risky sex because of the parental involvement laws, their 
Table 6. The Effect of Parental Involvement Laws on Male Teenage Gonorrhea Rates per 100,000 Population

\begin{tabular}{|c|c|c|c|}
\hline & $\begin{array}{c}\text { Hispanic gonorrhea } \\
\text { rate }_{\text {under } 20}\end{array}$ & $\begin{array}{c}\text { Black gonorrhea } \\
\text { rate }_{\text {under } 20}\end{array}$ & $\begin{array}{c}\text { White gonorrhea } \\
\text { rate under } 20\end{array}$ \\
\hline Involvement law & $-7.670(5.951)$ & 13.857 (35.129) & $-3.055(1.946)$ \\
\hline Gonorrhea rate $_{20+}$ & $0.238(0.018)^{\star \star \star}$ & $0.364(0.015)^{\star \star \star}$ & $0.316(0.022)^{\star \star \star}$ \\
\hline State effects & Yes & Yes & Yes \\
\hline Year effects & Yes & Yes & Yes \\
\hline State trends & Linear & Linear & Linear \\
\hline Observations & 911 & 912 & 912 \\
\hline$R^{2}$ & 0.947 & 0.941 & 0.933 \\
\hline
\end{tabular}

Robust SEs are given in parentheses. As above, all regressions are weighted using the population of males under the age of 20 for the given race for each state.

${ }^{* * *} p<0.01 ;{ }^{* *} p<0.05 ;{ }^{*} p<0.10$

male partners will also be limited in their opportunities for risky sex. However, since the burden of the involvement laws will fall on teenage girls, we should expect the effect to be mitigated for males, as they can always substitute toward having risky sex with older women who are unaffected by the laws. This substitution strategy will not be available to female teens.

The results presented in Table 6 are consistent with this as we find that both Hispanic and white male teenage gonorrhea rates are negatively related to the passage of a parental involvement law, though the effects are smaller than those observed for female gonorrhea rates and they are not statistically significant. Once again, however, we find black rates behaving differently, generating a positive coefficient on the parental involvement laws, though it is not statistically significant.

The results in Tables 2-6 provide robust evidence of the incentive effect of restricted abortion availability in teenagers' decisions regarding risky sex, at least for Hispanic and white teenage women. This suggests that Hispanic and white teenage women are forward looking in their sex decisions, and they systematically view informing their parents and obtaining parental consent as additional costs in obtaining an abortion, inducing them to engage in less risky sex when parental involvement laws are adopted. Unfortunately, the data do not allow us to differentiate between the possibility that teens engage in less sex and they simply have the same amount of sex but are more fastidious in their condom use. Both these causal mechanisms would generate the results we observe. Levine's (2003) results would suggest that the latter mechanism is driving our results, though we cannot rule out the possibility that both mechanisms are at work here. ${ }^{10}$ Along those lines, however, we can rule out the

10. To the extent that public opinion accurately reflects which causal mechanism is at work, in an October 1989 poll printed in the Parents magazine, 62\% of respondents indicated that they thought laws restricting abortion access for teens would make teens at least somewhat more likely to use contraception (compared to $35 \%$ who thought the laws would have no effect), whereas in the same poll, only $16 \%$ of respondents indicated that these laws would induce teens to curtail their sexual activity. 
possibility that teens simply substitute to risky sexual behaviors for which pregnancy is not a concern, such as oral or anal intercourse since these sets of behavior would also transmit gonorrhea. Further, more fastidious use of birth control pills also would not generate the effect we identify.

\section{Why Is There Racial Heterogeneity?}

In addition to our Hispanic and white results collectively suggesting that teen sexual behaviors respond to the additional costs generated by parental involvement laws, the black results collectively raise a puzzle. Not only do black gonorrhea rates exhibit the statistically significant systematic decline when parental involvement laws are adopted but also black male rates appear to rise and female rates appear to rise in the presence of a consent law and when a notification law is enjoined. The dynamics of gonorrhea rates among black teens appear to differ from those among Hispanics and whites.

These differential results could lead to a number of different inferences, but we are unable to choose among them on the basis of our analysis. Perhaps the fact that black gonorrhea rates are so much higher in general makes a difference in how much a behavioral change affects aggregate disease rates. Another possibility is that there is little cost involved with a young black woman informing her parents about her pregnancy. ${ }^{11}$ Perhaps there is more communication about sexual issues in black families, implying that the event of a pregnancy provides little new information about a child's sexual behavior. Also, perhaps black parents are less likely to view abortion negatively. There is some evidence on this point as some surveys indicate that black individuals are more likely than white and Hispanic individuals to believe that abortion should be legal. ${ }^{12}$ The high proportion of Hispanics who are Catholic could help to explain the relatively large effect of parental involvement laws on the behavior of Hispanic teens.

Even if none of those hypotheses is correct, it could be the case that black teens experience less disutility than their Hispanic and white counterparts when they disappoint their parents. Lastly, it could be the case that the relationships between black teens and their families does not systematically differ from the relationships in Hispanic and white families, but black teens have significantly higher discount rates that cause them to discount the future costs of sex (including parental disapproval) relatively more than teens from the

11. For example, Wells and Twenge (2005) find that black teens are significantly more likely to be sexually active than are white and Hispanic teens. In their study, they found that $62 \%$ of black teens were sexually active compared with only $40 \%$ of whites and $44 \%$ of Hispanics. Thus, it may be the case that notifying a black parent that her daughter is seeking an abortion provides relatively little new information about the daughter's sexual behavior since it was more likely than not that the daughter was sexually active. The same would not generally be true for white and Hispanic daughters.

12. Ladd and Bowman (1999) report 1992 and 1996 survey results suggesting that $67 \%$ of black individuals believed that abortion should be legal in most or all cases compared to $57 \%$ of Hispanics and $64 \%$ of whites in 1992 and 58\% of Hispanics and 58\% of whites in 1996. 
other groups, ${ }^{13}$ or perhaps there is more across age-group sex among black individuals than there is among Hispanic or white individuals. ${ }^{14}$

To get to the bottom of this heterogeneity, we examine the extent to which family structure influences our results. Census data are potentially enlightening here. It is clear that Hispanic and white families in the United States look very similar in terms of structure during the period we studied, at least relative to black families. For example, using data from the Household and Family Characteristics report that is part of the March Supplement to the Current Population Survey for the last year included in our study (1998), ${ }^{15}$ it would appear that the percent of family households that are headed by a married couple is much lower for blacks (47\%) than it is for either Hispanics $(69 \%)$ or whites (81\%). Excluding the Northeast, which has a relatively low percent of Hispanic family households headed by a married couple, the gap between blacks and the other two groups is even bigger. Arguably, the cost borne by a teenager for informing her parents about her sexual behavior will be higher in family households that are intact.

Unfortunately, census does not report family structure data at the state level, so it is not possible to control for family structure directly in our regressions. However, if we allow for results to differ by region, we might be able to discern whether the treatment effect of involvement laws differs in a way that makes sense in light of what we know about differences in family structure across regions. The most striking difference in family structure, as noted above, is found in a comparison of Hispanic households in the Northeast with Hispanic households in the rest of the country. In 1998, whereas the percent of Hispanic family households headed by a married couple for the Northeast was only $52 \%$, in the Midwest, South, and West it was 73\%, 74\%, and 71\%, respectively.

To analyze if these differences in Hispanic family structure lead to differences in treatment effects, we ran the regression from Table 2 above with three different sets of treatment effects. First, we performed one specification with a separate treatment effect for each region. The second specification allowed for a common treatment effect for the Midwest, the South, and the West and a separate treatment effect for the Northeast. Lastly, we estimated a regression with one general treatment effect for all four regions and a separate treatment effect for the Northeast. The results are presented in Table 7.

Our intuition about the effect of family structure appears to be consistent with our estimates. In the regression with four separate treatment effects, although all are negative, the coefficients for the Midwest, South, and West are all about twice as large in magnitude as the coefficient for the Northeast,

13. For some research regarding racial differences in discount rates, see Warner and Pleeter (2001), whose research suggests that blacks individuals exhibit systematically higher subjective discount rates compared to whites.

14. If there is significantly more sex between adults and teens among black individuals, parental involvement laws might have a large negative effect on the gonorrhea rate found among our contemporaneous control group, implicitly lowering the estimated treatment effect.

15. Available at http://www.census.gov/population/www/socdemo/hh-fam.html (last accessed on 21 July 2006). 
Table 7. Regional Treatment Effects for Hispanics

\begin{tabular}{llll}
\hline Involvement law_Northeast & $-6.516(18.464)$ & $-6.523(18.442)$ & $6.407(19.384)$ \\
Involvement law_Midwest & $-12.086(8.969)$ & - & - \\
Involvement law_South & $-15.345(8.727)$ & - & - \\
Involvement law_West & $-12.189(11.885)$ & - & - \\
Involvement law_Not NE & - & $-12.929(6.062)^{\star \star}$ & - \\
Involvement law & - & - & $-12.929(6.062)^{\star *}$ \\
Gonorrhea rate $_{20+}$ & $0.536(0.038)^{\star \star *}$ & $0.536(0.038)^{\star \star *}$ & $0.536(0.038)^{\star \star *}$ \\
State effects & Yes & Yes & Yes \\
Year effects & Yes & Yes & Yes \\
State trends & Linear & Linear & Linear \\
Observations & 911 & 911 & 911
\end{tabular}

Robust SEs are given in parentheses. All regressions were weighted using the population of Hispanic females under the age of 20 for each state.

${ }^{\star \star \star} p<0.01 ;{ }^{\star \star} p<0.05 ;{ }^{\star} p<0.10$

though the difference is not statistically significant owing to the large SEs. In the specification that pools the effects in the Midwest, South, and West allowing for a separate Northeast effect, we find that the non-Northeast effect is statistically significant and it is twice as large as the treatment effect in the Northeast, though the difference between the coefficients is still not statistically significant. Lastly, we find the same basic result in the specification that allows for a generic effect for all regions plus an additional effect for the Northeast, finding a statistically significant negative generic treatment effect and a positive treatment effect for the Northeast that is not statistically significant.

These results may provide some general clues as to our failure to find a statistically significant treatment effect for black teens, given that they are much more likely to live in households where two parents are not present. However, it is not possible to test this intuition in even the indirect way described above since there are no stark differences in black family structure across regions. ${ }^{16}$

\section{Conclusion}

Incentives matter. They matter even in activities as primal as sex, and they matter even among teenagers, who are conventionally thought to be short-sighted. If the expected costs of risky sex are raised, teens will substitute toward less risky activities such as protected sex or abstinence. In addition to modeling the decision-making processes of teenagers, this insight is important in other contexts as well. Many public policies can be improved by recognizing the sensitivity of teenage sexual decisions to costs and benefits.

We study one set of policies in this article. We show that increasing the cost of abortion for teens lowers the insurance value of abortion. This induces

16. For example, in 1998 , the percent of black family households headed by a married couple was $43,45,48$, and 50, respectively, for the Northeast, Midwest, South, and West. 
teenage girls to avoid risky sex, which will likely have the effect of lowering pregnancy rates, abortion rates, and birth rates among this group of individuals. Although these positive effects alone might not justify parental involvement laws, they presumably should not be ignored in the debate. ${ }^{17}$ Behavior is not static, and claims based on the assumption of static behavior are flawed.

From a practical standpoint, this study reinforces the claim made in Klick and Stratmann (2003) that epidemiologists could improve models of the spread of STDs by incorporating the behavioral effects induced by changes in abortion access. However, those effects may differ by race, religion, or family structure, and more research is needed to determine the relative contribution of these factors to the behavioral effects of abortion access.

From an academic standpoint, our results support the conclusion reached in Levine (2004) that teens do view abortion as pregnancy insurance and the enactment of parental involvement laws induces teens to substitute away from risky sex. Although being consistent with the Levine results, by focusing on gonorrhea rates instead of abortion and pregnancy rates, we avoid the data problem posed by illegal, informal, and out-of-state abortions which limit confidence in the earlier studies.

\section{References}

Arellano, Manuel, and Stephen Bond. 1991. "Some Tests of Specification for Panel Data: Monte Carlo Evidence and an Application to Employment Equations," 58 Review of Economics and Statistics 277-97.

Ayres, Ian, and Katharine Baker. 2005. “A Separate Crime of Reckless Sex," 72 University of Chicago Law Review 599-666.

Baumeister, Roy, and Kathleen Vohs. 2004. "Sexual Economics: Sex as Female Resource for Social Exchange in Heterosexual Interactions," 8 Personality and Social Psychology Review 339-63.

Bertrand, Marianne, Esther Duflo, and Sendhil Mullainathan. 2004. "How Much Should We Trust Differences-in-Differences Estimates?,” 119 Quarterly Journal of Economics 249-75.

Bitler, Marianne, and Madeline Zavodny. 2001. "The Effect of Abortion Restrictions on the Timing of Abortions," 20 Journal of Health Economics 1011-32.

Blank, Rebecca, Christine George, and Rebecca London. 1996. "State Abortion Rates: The Impact of Policies, Providers, Politics, Demographics, and Economic Environment," 15 Journal of Health Economics 513-53.

Dee, Thomas, and Bisakha Sen. 2006. “Do Abortion Restrictions Reduce Risky Teen Sex: Evidence from Parental Involvement Laws.” Working Paper, Swarthmore College.

Greene, William. 2000. Econometric Analysis. 4th ed. Upper Saddle River, N.J.: Prentice Hall. Haas-Wilson, Deborah. 1996. “The Impact of State Abortion Restrictions on Minors' Demand for Abortions," 31 Journal of Human Resources 140-58.

Joyce, Theodore, and Robert Kaestner. 1996. "State Reproductive Policies and Adolescent Pregnancy Resolution: The Case of Parental Involvement Laws," 15 Journal of Health Economics 579-607.

Joyce, Theodore, Robert Kaestner, and Silvie Colman. 2006. "Changes in Abortions and Births and the Texas Parental Notification Law," 354 New England Journal of Medicine $1031-38$.

17. It might even be the case that these results are suggestive of an "undue burden" in the constitutional analysis of parental involvement laws. 
Klick, Jonathan. 2004. "Econometric Analyses of U.S. Abortion Policy: A Critical Review," 31 Fordham Urban Law Journal 751-82.

Klick, Jonathan, and Thomas Stratmann. 2003. "The Effect of Abortion Legalization on Sexual Behavior: Evidence from Sexually Transmitted Diseases," 32 Journal of Legal Studies 407-33.

Ladd, Everett, and Karlyn Bowman. 1999. Public Opinion About Abortion. Washington, D.C.: AEI Press.

Levine, Phillip. 2004. "Parental Involvement Laws and Fertility Behavior," 22 Journal of Health Economics 861-78.

Levine, Phillip, and Douglas Staiger. 2004. "Abortion Policy and Fertility Outcomes: The Eastern European Experience," 47 Journal of Law \& Economics 223-44.

Loewenstein, George. 1996. "Out of Control: Visceral Influences on Behavior," 65 Organizational Behavior and Human Decision Processes 272-92.

Loewenstein, George, and Frank Furstenberg. 1991. "Is Teenage Sexual Behavior Rational?," 21 Journal of Applied Social Psychology 957-86.

Medoff, Marshall. 1999. "An Estimate of Teenage Abortion Demand," 28 Journal of SocioEconomics, 175-84.

Merz, Jon, Catherine Jackson, and Jacob Klerman. 1995. “A Review of Abortion Policy: Legality, Medicaid Funding, and Parental Involvement, 1967-1994,” 17 Women's Rights Law Reporter $1-61$.

Schrag, Peter. 2005. "Parental Consent: The Sleeper in the Abortion Fight." Sacramento Bee, July 6 .

Sen, Bisakha. 2003. "A Preliminary Investigation of the Effects of Restrictions on Medicaid Funding of Abortions on Female STD Rates," 12 Health Economics 453-64.

Stock, James, and Mark Watson. 2003. Introduction to Econometrics. New York: AddisonWesley.

Tomal, Annette. 1999. "Parental Involvement Laws and Minor and Non-Minor Teen Abortion and Birth Rates," 20 Journal of Family and Economic Issues 149-62.

Warner, John, and Saul Pleeter. 2001. "The Personal Discount Rate: Evidence from Military Downsizing Programs," 91 American Economic Review 33-53.

Weinstock, Hillard, Stuart Berman, and Willard Cates. 2004. "Sexually Transmitted Diseases Among American Youth: Incidence and Prevalence Estimates, 2000," 36 Perspectives on Sexual and Reproductive Health 6-10.

Wells, Brooke, and Jean Twenge. 2005. "Changes in Young People's Sexual Behavior and Attitudes, 1943-1999: A Cross-Temporal Meta-Analysis," 9 Review of General Psychology 249-61.

Wooldridge, Jeffrey. 2003. Introductory Economics: A Modern Approach. 2nd ed. Mason, Ohio: Thomson-Southwestern. 